\title{
Performance of PID Controller Tuning based on Particle Swarm Optimization and Firefly Algorithm
}

\author{
N.A. Selamat, T.O. Ramih, A. R. Abdullah, M. S. Karis
}

\begin{abstract}
This paper shows the study of tuning the Proportional-Integral-Derivatives (PID) in the application of coupled tank system. The controller was tuned by using an optimization technique which is a Firefly Algorithm (FA) and a Particle Swarm Optimization (PSO) Algorithm. Both FA and PSO performance were evaluated by using performance index of Integral Time Square Error (ITSE). The systems response of FA and PSO were gathered and compared in term of transient responses, ITSE and standard deviation by considering the system condition of with and without a disturbance. The simulation is conducted by using MATLAB software. The result shows that the FA giving a better system performance compared to PSO in term of overall transient responses.
\end{abstract}

Keywords: Coupled Tank System (CTS), Firefly Algorithm, ITSE, PID Controller, Particle Swarm Optimization, Parameter Tune.

\section{INTRODUCTION}

In studying the behavior or performance of a controller, the coupled tank system is one of the favorable application. It has become a benchmark apparatus in studying the process control engineering where its applications are widely used in industries of Petro-chemical, waste water treatment and purification, biochemical, spray coating, beverages and pharmaceutical industries [1]. This is due to its simple construction with an additional advantage of easy configuration manipulation to form some complex systems. Previously, there are several types of controller that has been implemented to the coupled tank system which are Linear Quadratic Regulator (LQR), PID and Fuzzy logic controller (FLC). Amongst that, LQR is an example of controller that could manage the dynamic of the system with minimal cost. Research by [2] had compare the implementation of two controllers of LQR and PID to the coupled tank system. Based on the results of ITSE and the summation of the overall transient response, it shows that LQR has minimal ITSE compared to PID controller which lead to better transient response performance. While study by [3] used the coupled tank system to investigate the performance of Fuzzy

Revised Manuscript Received on October 25, 2019

* Correspondence Author

Nur Asmiza Selamat*, Universiti Teknikal Malaysia Melaka (UTeM), Melaka Malaysia. Email: nurasmiza@utem.edu.my

Tarmizi Omar Ramih Universiti Teknikal Malaysia Melaka (UTeM), Melaka Malaysia.

Abdul Rahim Abdullah, Universiti Teknikal Malaysia Melaka (UTeM), Melaka Malaysia.

Mohd Safirin Karis, Universiti Teknikal Malaysia Melaka (UTeM), Melaka Malaysia.

controller and PID controller. The PID controller has been selected due to its previous successful record in controlling wide range of system, while fuzzy controller was said to be more robust, stable, has low computational requirement and less input dependent with an additional advantage of fast response and small overshoot. The listed advantage of fuzzy logic controlled had been proven by the experimentation results in [3] at which the fuzzy controller is more stable, has less overshoot and provide faster respond compare to PID controller. Nevertheless, this study aims to compare the systems performance based on two tuning methods, hence PID controller is selected due to its simple control model.

According to its name PID is based on three mathematical expressions that are proportional, integral and derivatives which then combine as one equation. The three term in PID were then manipulated to left only a constant parameter to be tuned. Finding balance in all three parameters could lead to good system performance, yet its challenging task. In literature several methods of controller parameter tuning had been proposed such as trial and error, auto-tune, Ziegler Nichols (ZN), Cohen-Coon (CC), standard PSO and PSO, which also have been implemented by [4] where the result shows that tuning using optimization technique improve the system performance. There is a wide variation of optimization technique available, however, an adjustment of optimization parameters is also required. For example, for genetic algorithm the involve parameters are mutation probability and crossover probability. While for PSO parameter such as inertia weight and constant "c" need to be firstly pre-determined. All those parameters could also the performance of the optimization technique and controller performance. With that, the study and development of optimization techniques are still an on-going research with the aims of finding the powerful algorithms in estimating the optimal parameters that could compensate the different applications with various conditions probability and providing the best system performance [5].

This study aiming to search for the suitable combination of all three controller parameters by using optimization technique of FA and PSO. FA and PSO are a metaheuristic bioinspired algorithm and choose to be used in this study as the FA has been proven on its capability to deal with wide range areas [6], while PSO is known to be establish algorithm for more than twenty decades with simple algorithms [7].

Generally, this paper presents the experimentation of FA and PSO tuning method for PID controller by using coupled tank system. 
A robustness test was also performed by introducing a random disturbance to the systems.

\section{COUPLED TANK SYSTEM}

This study used the coupled tanks system of CTS-001 model as describe in [8]. The typical model of coupled tanks system as shown in Fig. 1 is based on combination of two cylindrical tanks, orifice as a connector tanks, baffle as a separator, individual pump as input and individual release as an output. The configuration of the coupled tank system could be change by manipulating the baffle, input pump and release valve. The input pump could be driven by using direct voltage of 0 to $5 \mathrm{~V}_{\mathrm{dc}}$ or pulse width modulation (PWM) source.

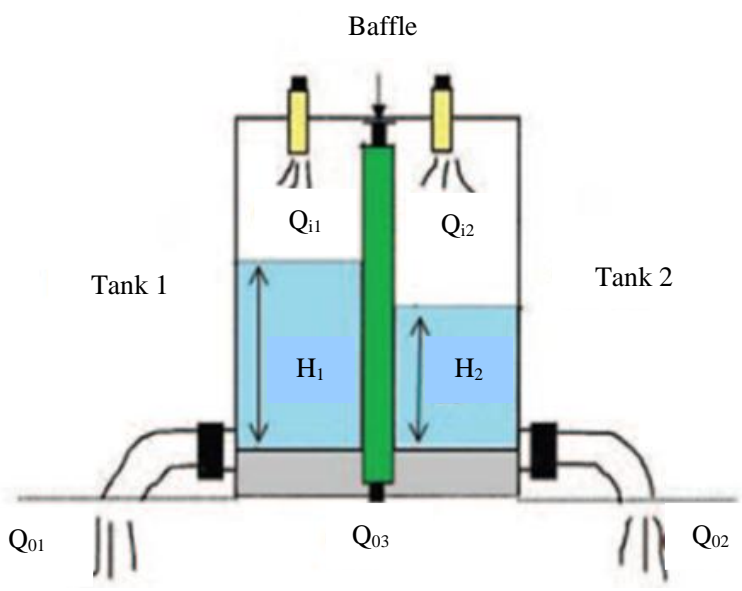

Fig. 1. Schematic diagram of Coupled Tank [8].

For this study, the configuration of the coupled tank system is based on the simple model of second order single-input single-output (SISO) coupled tanks is used where the equation is derived by using a mass balance equation with the rate of change and the net flow of liquid is assuming to be equal. The mass balance equation is shown in (1) and (2).

$$
\begin{aligned}
& A_{1} \frac{d H_{1}}{d t}=Q_{i 1}-Q_{o 1}-Q_{o 3} \\
& A_{2} \frac{d H_{2}}{d t}=Q_{i 2}-Q_{o 2}-Q_{o 3}
\end{aligned}
$$

Where $\mathrm{A}_{1}$ and $\mathrm{A}_{2}$ is respective tank 1 and tank 2 cross-sectional area, $\mathrm{H}_{1}$ and $\mathrm{H}_{2}$ is respective fluid height of tank 1 and tank $2, \mathrm{Q}_{\mathrm{i} 1}$ and $\mathrm{Q}_{\mathrm{i} 2}$ is respective pump flow rate for tank 1 and tank $2, \mathrm{Q}_{\mathrm{o} 1}$ and $\mathrm{Q}_{\mathrm{o} 2}$ is respective output flow rate and $\mathrm{Q}_{03}$ is liquid flow rate in between tank 1 and tank 2 .

For second order SISO configuration, $\mathrm{h}_{2}$ is functioning as process variable, $\mathrm{q}_{\mathrm{i} 1}$ as the manipulated variable and the initial condition of $\mathrm{q}_{2}$ is assume to be equal to zero. The second-order system used in the study is shown in Fig. 2 while the parameter variable is shown in Table I. The variable value shown in Table I is then substituted to (3) and form the mathematical equation of (4) that will further use for analyzing the systems.

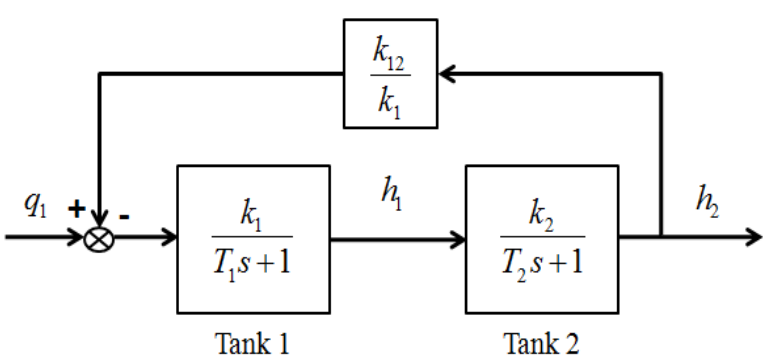

Fig. 2. Block Diagram of Coupled Tank System under investigation

Table- I: Parameter Variable of Coupled-Tank [8]

\begin{tabular}{|c|c|}
\hline Variable & Value \\
\hline $\mathrm{H}_{2}$ & $15 \mathrm{~cm}$ \\
\hline$\alpha_{1}$ & $10.78 \mathrm{~cm}^{3 / 2} / \mathrm{sec}$ \\
\hline$\alpha_{2}$ & $11.03 \mathrm{~cm}^{3 / 2} / \mathrm{sec}$ \\
\hline$\alpha_{3}$ & $11.03 \mathrm{~cm}^{3 / 2} / \mathrm{sec}$ \\
\hline $\mathrm{A}_{1}$ & $32 \mathrm{~cm}^{2}$ \\
\hline $\mathrm{A}_{2}$ & $32 \mathrm{~cm}^{2}$ \\
\hline
\end{tabular}

$$
\begin{aligned}
\frac{h_{2}(s)}{q_{1}(s)} & =\frac{k_{1} k_{2}}{\left.T_{1} T_{2} s^{2}+\left(T_{1}+T_{2}\right) s+1-k_{12} k_{21}\right)} \\
G_{p}(s) & =\frac{h_{2}(s)}{q_{1}(s)}=\frac{0.000977}{s^{2}+0.3291 s+0.1222}
\end{aligned}
$$

\section{PID CONTROLLER}

The working principles of PID controller is based on control loop feedback controller and consist of three constant parameters of $\mathrm{Kp}, \mathrm{Ki}$ and $\mathrm{Kd}$, the constant is requiring to be properly tuned so that the system could be functioning at its best. PID as a whole could be interpret as controller that estimating the system performance based on prediction of an overall error of present, past and future. The assumption is based on $\mathrm{P}$ represent as a present error that used to reduce the error, I represent the past that used to eliminates the error and $D$ represent the future error that used to speed up the response. [9]. Hence, the optimal constant value of the PID controller could improve the system performance. The PID equation used in this paper is shown in (5).

$$
G_{C}(s)=K_{p}+\frac{K_{i}}{s}+K_{d} s
$$

where $K_{p}$ is proportional constant $(\mathrm{P}), K_{i}$ is Integral constant (I) and $K_{d}$ is Derivative constant (D).

\section{OPTIMIZATION TECHNIQUES}

In this study two optimization techniques have been chosen as controller tuning which are FA and PSO. The details of the algorithm are described below:

\section{A. Firefly Algorithm (FA)}

FA algorithm is developing by Dr. Xin She Yang in late 2007 and early 2008. It is a nature inspired meta-heuristic and adapted according the flashing pattern and behavior of firefly. In developing the algorithm, 
the FA behavior could be describe based on three main concepts that's are:

i) A group of firefly that could flash the brightest light will attract the other firefly to join the group without considering the gender.

ii) Firefly attractiveness is proportional to brightness. The brightness of a group of firefly increase as the distance in between each firefly decrease. Individual firefly will fly randomly.

iii) The brightness or attractiveness of firefly depends on a landscape of the objective function.

The FA algorithm is represented in a mathematical expression of (6). The attractiveness is measure based on $\beta$ with ' $r$ ' is the distance between firefly. During initialization $\beta o$ is declared as attractiveness variation at $r=0$. The ' $i$ ' firefly will be attracted to brighter firefly ' $\mathrm{j}$ ', where the attractiveness is measure based on (7). Besides that, in (7) the second term is due to the attraction while the third term referring to randomization of $\alpha$ t which is represent the randomization parameter and $\epsilon$ it is define as vector of random numbers drawn from a Gaussian distribution or uniform distribution at time $t$.

$$
\begin{gathered}
\beta=\beta_{o} e^{-\gamma r 2} \\
X_{i}^{t+1}=X_{i}^{t}+\beta_{o} e^{-\gamma r 2 i j}\left(X_{i}^{t}-X_{j}^{t}\right)+\alpha_{t} \epsilon_{i}^{t}
\end{gathered}
$$

\section{B. Particle Swarm Optimization (PSO)}

In 1995, PSO had been designed by Kennedy and Eberhard. The founders were inspired by the flock of bird communication method during food search. It is one of the heuristic global optimization method. A PSO represents the particles as the bird, while the swarm particles represented by a flock of bird. During the food search, the birds will search the targeted area that has a potential food source and communicate with one another based on the flock. The concepts were then being translated to the PSO algorithm by representation of particles that move through a multi-dimensional search space while maintaining as a swarm of particles. Each particle could become the potential solution. The particle movement are based on calculation of its velocity and its position based on (8) and (9) respectively. The velocity and the position were updated accordingly either based on its own experience and the successful experiences of its neighbors.

$$
\begin{array}{r}
, k+1=w_{k} V_{i, k}+c_{1} r_{1}\left(P_{\text {pbest }, i, k}-X_{i, k}\right)+c_{2} r_{2}\left(P_{\text {gbest }, i,}\right. \\
\left.-X_{i, k}\right) \\
X_{i, k+1}=X_{i, k}+V_{i, k+1} \\
w_{k}=w_{\text {max }}-\left(\left(\text { iteration } *\left(w_{\text {max }}-w_{\text {min }}\right) /\right.\right. \\
\text { maxiteration })
\end{array}
$$

where $v_{i}^{k}$ is Velocity of the $i^{\text {th }}$ individual at iteration $k$, $w_{k}$ is Inertia weight at iteration $k, r_{1}$ and $r_{2}$ random number of $[0,1]$.

\section{SIMULATION PROCESS}

The simulation was executed for 20 times due to its stochastic characteristic. The data that collected from the simulation are the tuned parameter and the objective function which is ITSE value. The final parameter tuning is determined based on execution that contribute to the minimum ITSE among the 20 executions. Apart from that the simulation was repeatedly executed for 10 times to obtain the standard deviation of the ITSE value. Several criteria need to be determined before the data for performance evaluation start to be gathered. Those criteria are the optimization technique parameter termination, the stopping criteria and performance evaluation that taken into consideration in this paper. All criteria are discussed below.

\section{A. FA and PSO parameter determination}

This study aims to make a fair comparison of performance analysis between FA and PSO, hence the selection of parameter needs to be considered. Two parameter selection that being taken into consideration is number of population and the upper boundary. Both of the parameters are important as it will affect the simulation run time and suitability of the parameter range that will lead to system performance. The chosen parameter for both FA and PSO is shown in II.

Table- II: Optimization Parameters Value

\begin{tabular}{|c|c|}
\hline Parameter & Value \\
\hline Population Numbers & 20 \\
\hline Upper Boundary & 100000 \\
\hline
\end{tabular}

\section{B. Stopping Criteria}

For the purpose of this study, two out of several criteria which has been listed by [10] is chosen that is no improvement observed over a number of iterations and when the number of maximum iterations has been reached. The reason of this selection is to reduce the simulation time while maintaining the probability in finding an optimal parameter selection.

Generally, both of the stopping criteria work with OR conditions, with the means of if either one of the stopping criteria is met, the iteration or simulation will be stop. The first condition can be defined as when there is no improvement of the objective function after a number of iterations that has been set. The second condition is when the number of iteration is reaching its maximum set-up value.

\section{PERFORMANCE EVALUATION}

The purpose of this study is to evaluate the system performance of according to FA and PSO as the parameter tuning applied in PID controller. Hence, few analyses have been taken into consideration in determining which optimization techniques will provide an optimal system performance of transient's response. Further analysis of the systems of this paper are shown in III. In III, ITSE is defined as integral Times Square Error where the equation is shown in (10). 
Table- III: Performance Analysis of FA and PSO as Parameter Tuning

\begin{tabular}{|c|c|c|}
\hline Analysis & Performance analysis & Measurement Tools \\
\hline $\mathbf{1}$ & $\begin{array}{c}\text { System without } \\
\text { Disturbance }\end{array}$ & $\begin{array}{c}\text { ITSE and Transient } \\
\text { Response }\end{array}$ \\
\hline $\mathbf{2}$ & System with disturbance & $\begin{array}{c}\text { ITSE and Transient } \\
\text { Response }\end{array}$ \\
\hline $\mathbf{3}$ & Precision & ITSE Standard Deviation \\
\hline
\end{tabular}

$$
\operatorname{ITSE}=\int_{0}^{t}\left(e_{i}(t)\right)^{2} t d t
$$

\section{RESULTS AND DISCUSSION}

As stated previously the result will be analyzed according three main analyses. Further discussions are as follows:

\section{A. Analysis 1: System without Disturbance}

In this paper the best tuned controller parameter determines, after 20 executions. Result, based on the best performance index, which indicates by the minimum ITSE value amongst 20 executions are from FA is 0.1092 and PSO is 0.1360. According to the result, the tuned control parameter that contributed to the following presented ITSE is shown in IV and the transient response is shown in Fig. 3. The details of transient response of the system are shown in $\mathrm{V}$. The response data and its ITSE value were then plotted in a graph shown in Fig. 4. Based on the result, both FA and PSO are able to optimize or tuned the controller parameter. By comparing both of the result FA gives better system performance in term of the objective function and overall transient responses.

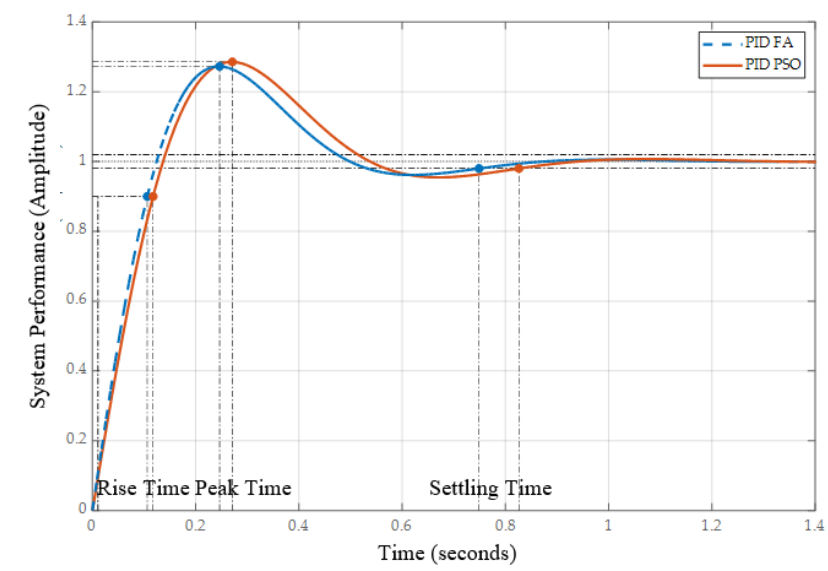

Fig. 3. System Transient Response without Disturbance

Table- IV: PID Controller Tuned Parameter without Disturbance

\begin{tabular}{|c|c|c|c|c|}
\hline Algorithm & ITSE & $\mathbf{K}_{\mathbf{p}}$ & $\mathbf{K}_{\mathbf{i}}$ & $\mathbf{K}_{\mathbf{d}}$ \\
\hline FA & 0.1092 & 100000 & 90.4224 & 10376.7023 \\
\hline PSO & 0.1360 & 84504.3145 & 1748.4844 & 9073.7754 \\
\hline
\end{tabular}

Table- V: System Performance with PID Controller without Disturbance

\begin{tabular}{|c|c|c|c|c|}
\hline $\begin{array}{c}\text { Transient } \\
\text { Response }\end{array}$ & $\begin{array}{c}\text { Rise Time, } \\
\text { Tr (s) }\end{array}$ & $\begin{array}{c}\text { Peak Time, } \\
\text { Tp (s) }\end{array}$ & $\begin{array}{c}\text { Settling Time, } \\
\text { Ts (s) }\end{array}$ & $\begin{array}{c}\text { Overshoot } \\
(\boldsymbol{\%})\end{array}$ \\
\hline FA & 0.0963 & 0.2464 & 0.7489 & 27.2524 \\
\hline PSO & 0.1062 & 0.2710 & 0.8260 & 28.5352 \\
\hline
\end{tabular}

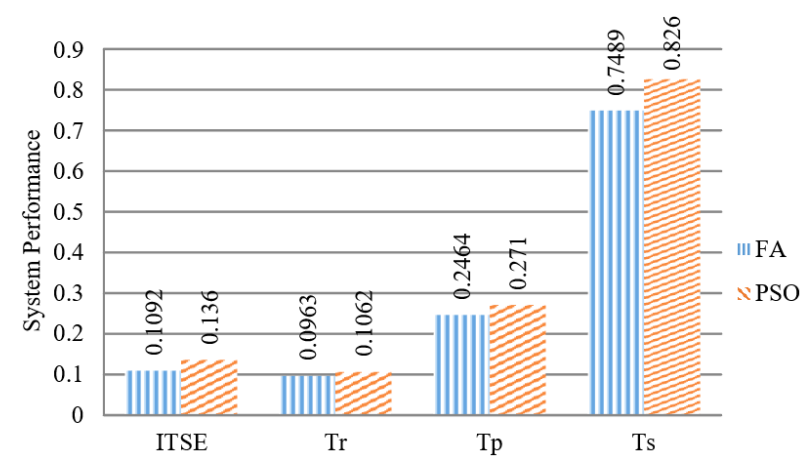

Fig. 4. System Performance without Disturbance

\section{B. Analysis 2: System with Disturbance}

To test the system disturbance rejection for PID controller tuned using FA and PSO, the system was injected with signal generator disturbance input available in the MATLAB.

The result of tunes parameter with disturbance is shown in VI, where the best performance index, which indicates by minimum ITSE value of 20 executions for FA is 0.10433 and PSO is 0.1236 . According to the result, the tuned control parameter that contributed to the following presented ITSE is shown in VII and the transient response is shown in Fig. 5. The details of transient response of the system are shown in VII. The response data and its ITSE value were then plotted in a graph shown in Fig. 6. Based on the result, both FA and PSO are able to provide a good PID parameter. By comparing both of the result by observation FA provide slightly smaller ITSE comparable to PSO. But in terms of transient response PSO provide slightly better in term of Tr, Tp and Ts. But since ITSE is representation overall performance, hence it can be concluded that FA also provide better tuned parameter compared to PSO.

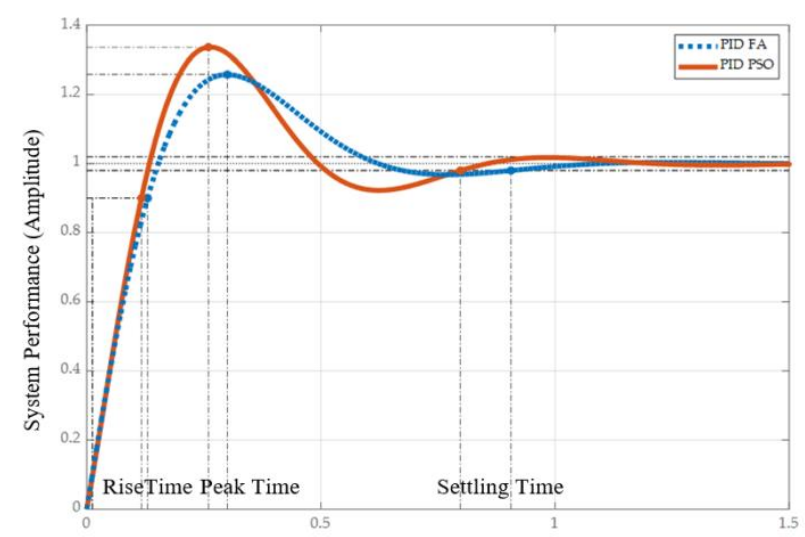

Fig. 5. System Performance with Disturbance

Table- VI: PID Controller Tuned Parameter with Disturbance

\begin{tabular}{|c|c|c|c|c|}
\hline Algorithm & ITSE & $\mathbf{K}_{\mathbf{p}}$ & $\mathbf{K}_{\mathbf{i}}$ & $\mathbf{K}_{\mathbf{d}}$ \\
\hline FA & 0.1043 & 65917.7704 & 70.6973 & 8770.0497 \\
\hline PSO & 0.1236 & 94772.4497 & 248.8234 & 8012.1542 \\
\hline
\end{tabular}

Table- VII: System Performance with PID Controller with Disturbance

\begin{tabular}{|c|c|c|c|c|}
\hline $\begin{array}{c}\text { Transient } \\
\text { Response }\end{array}$ & $\begin{array}{c}\text { Rise Time, } \\
\text { Tr (s) }\end{array}$ & $\begin{array}{c}\text { Peak Time, } \\
\text { Tp (s) }\end{array}$ & $\begin{array}{c}\text { Settling Time, } \\
\text { Ts (s) }\end{array}$ & $\begin{array}{c}\text { Overshoot } \\
(\mathbf{\%})\end{array}$ \\
\hline FA & 0.1180 & 0.3002 & 0.9058 & 25.7719 \\
\hline PSO & 0.1042 & 0.2597 & 0.7980 & 33.6210 \\
\hline
\end{tabular}




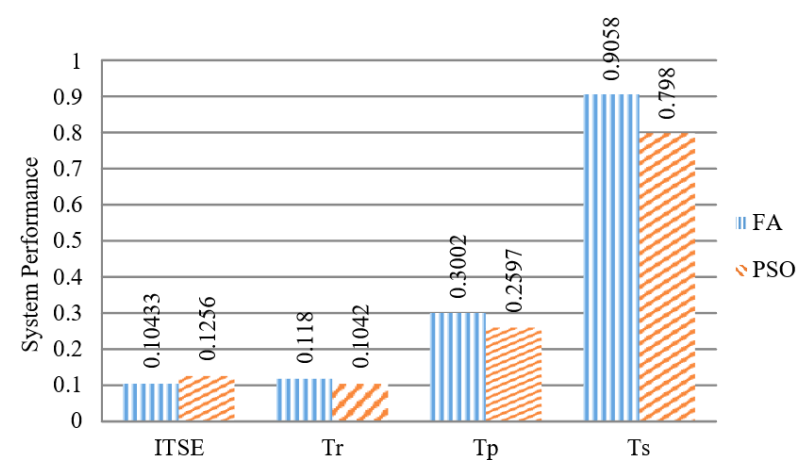

Fig. 6. System Performance with Disturbance

\section{Analysis 3: Precision}

Both of the optimization technique is categorized as stochastic search, which give different values for each MATLAB execution. Hence, for this research the simulation repeatedly executed for 10 times for system with and without disturbance. In order to test the precision of optimization technique, statistical data which are the standard deviation of the ITSE was studied. The result of standard deviation of ITSE for both systems with and without disturbance is tabulated in VIII and plotted in Fig. 7. Based on the result, it shows that both the FA and PSO provide precise data as the values between FA and PSO for systems with and without disturbance are nearly same

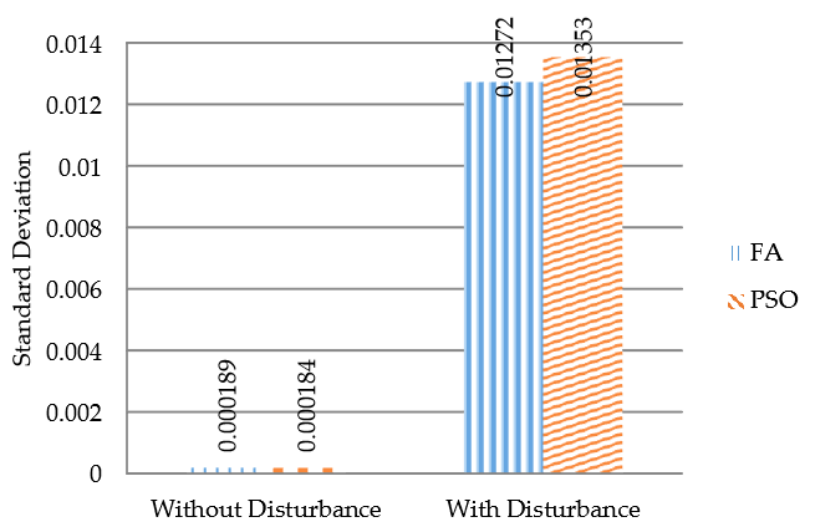

Fig. 7. Statistical Analysis (standard deviation)

Table- VIII: Statistical Data for 10 Times Execution

\begin{tabular}{|l|c|c|c|c|}
\hline & \multicolumn{2}{|c|}{ Without disturbance } & \multicolumn{2}{c|}{ With Disturbance } \\
\hline $\begin{array}{l}\text { Optimization } \\
\text { Technique }\end{array}$ & FA & PSO & FA & PSO \\
\hline Mean & 0.119328 & 0.155900 & 0.112409 & 0.155096 \\
\hline Standard Dev. & 0.000189 & 0.000184 & 0.012720 & 0.013530 \\
\hline
\end{tabular}

\section{CONCLUSION}

Study had shown that PID controller is still maintain its functionality compared to others controller due to its simplicity. However, in order for PID to act as at its best selecting proper tuning method are crucial.

In this paper comparison between two optimization techniques as the parameter tuning has been done. The comparisons are categorized based on three analyses, which are system without disturbance, system with disturbance and precision. Method for comparison of systems with and without disturbance is based on ITSE and transient response value. While for precision, are based on statistical analysis of standard deviation.

Based on the result, it can be concluded that both FA and PSO are able to tune the CTS system in a condition with and without disturbance. The result also shows that the FA and PSO can provide precise and reliable data. Lastly, it could be summarizing that the tuning method does affect the system performance and in this study, FA contribute to slight improvement of systems response of ITSE in comparison of PSO.

\section{ACKNOWLEDGMENT}

The authors would like to show an appreciation to Universiti Teknikal Malaysia Melaka (UTeM) and to the Ministry of Higher Education Malaysia (MOHE) for support this reseach and providing a funding of GLuar/STEVIA/2016/FKE-CERIA/I00009. Their support is gratefully acknowledged.

\section{REFERENCES}

1. Auwal Shehu Tijjani, Muhammad Auwal Shehu, Ali Mohsen Alsabari, Yusuf A Sambol and Nuradeen Labaran Tanko, "Performance Analysis for Coupled - Tank System Liquid Level Control Using MPC, PI and PI-plus-Feedforward Control Scheme", Journal of Robotics and Automation, vol. 1, no. 1, pp. 42-53, 2017.

2. N. A. Selamat, F. S. Daud, H. I. Jaafar, and N. H. Shamsudin "Comparison of LQR and PID Controller Tuning Using PSO for Coupled Tank System, "in 2015 IEEE 11th International Colloquium on Signal Processing \& its Application (CSPA2015), Kuala Lumpur, Malaysia, 2015 ,

3. H. Kala, D. Deepakraj, P. Gopalakrishnan, P. Vengadesan, and M K.Iyyar. "Performance Evaluation of Fuzzy Logic and PID Controller for Liquid Level Process", International Journal of Innovative Research in Electrical, Electronics, Instrumentation and Control Engineering, vol. 2, no. 3, pp. 1311-1314, 2014.

4. H. I. Jaafar, S. Y. S. Hussien, N. A. Selamat, M. N. M. Nasir and M. H. Jali, "Analysis of Transient Response for Coupled Tank System via Conventional and Particle Swarm Optimization (PSO) Techniques", International Journal of Engineering and Technology (IJET), vol. 6, no. 5, pp. 2002-2007, 2014.

5. Mohamed Louzazni, Ahmed Khouya, Khalid Amechnoue, Alessandro Gandelli, Marco Mussetta and Aurelian Craciunescu, "Metaheuristic Algorithm for Photovoltaic Parameters: Comparative Study and Prediction with a Firefly Algorithm", Applied Sciences, vol. 8, no. 339, pp. 1-22, 2018.

6. Yang, X.-S.; He and X.-S., "Why the Firefly Algorithm Works? In Nature-Inspired Algorithms and Applied Optimization, "Springer: Cham, Switzerland, pp. 245- 259, 2018.

7. Saptarshi Sengupta, Sanchita Basak and Richard Alan Peters II "Particle Swarm Optimization: A Survey of Historical and Recent Developments with Hybridization Perspectives,"Machine Learning \& Knowledge Extraction, vol. 1, pp. 157-191, 2018.

8. Manual Book of Couple Tank Liquid Level System (CTS-001), Augmentad Innovation Sdn. Bhd

9. T. Slavov and O. Roeva, "Application of Genetic Algoritmn to Tuning a PID controller for Glucose Concentration Control, "WSEAS Transactions on System, vol. 11, no. 7, pp. 223-233, 2012.

10. D. P. Rini, S. M. Shamsuddind, and S. S. Yuhainiz, "Particle Swarm Optimization: Technique, System and Challenges, "International Journal of Computer Application, vo.4, no. 7, 2011.

\section{AUTHORS PROFILE}

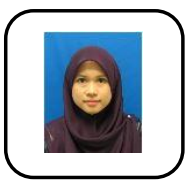

Nur Asmiza Selamat received her Bachelor degree in Electrical Engineering from Universiti Teknolog Malaysia (UTM), in 2009. She received her M.Eng degree in Mechatronics and Automatic Control engineering also from UTM, in 2013. She is a Lecturer at Universiti

Teknikal Malaysia Melaka (UTeM) and currently pursuing her $\mathrm{PhD}$ in Universiti Kebangsaan Malaysia, UKM. 
Performance of PID Controller Tuning based on Particle Swarm Optimization and Firefly Algorithm

Tarmizi Omar Ramih received her Bachelor in Electrical Engineering in Control, Instrumentation and Automation from Universiti Teknikal Malaysia Melaka (UTeM), in 2016

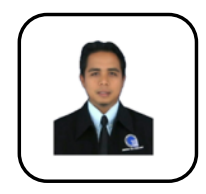

Associate Professor. Ir. Dr. Abdul Rahim Abdullah is an Associate Professor in Universiti Teknikal Mlaysia Melaka (UTeM). He received his $\mathrm{PhD}$ in Power Engineering and Digital Signal Processing from Universiti Teknologi Malaysia (UTM). He is Certified Energy Manager

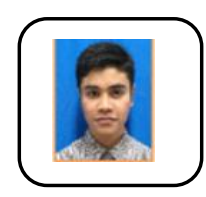

Ir. Mohd Safirin Karis received his B. Eng. (Electrical Engineering - Telecommunications) from Universiti Teknologi Malaysia (UTM), in 2009. He received his M.Eng degree in Mechatronics and Automatic Control engineering also from UTM, in 2013. Currently, he is a (UTeM).

Senior Lecturer at Universiti Teknikal Malaysia Melaka 